\title{
IMPACTOS DO NEOLIBERALISMO E DA REFORMA EMPRESARIAL DA EDUCAÇÃO SOBRE $O$ TRABALHO DOCENTE
}

\author{
*Ana Carla Vaz Porto \\ Mestranda em Educação na PUC GO, 62 3946-1674
}

\section{ARTICLE INFO}

\section{Article History:}

Received $11^{\text {th }}$ February, 2021

Received in revised form

$26^{\text {th }}$ March, 2021

Accepted $17^{\text {th }}$ April, 2021

Published online $22^{\text {th }}$ May, 2021

\section{Key Words:}

Neoliberalismo; Precarização;

Trabalho; Docente.

\begin{abstract}
O presente artigo têm por objetivo demonstrar como o neoliberalismo e a reforma empresarial da educação no Brasil têm protagonizado a precarização dos direitos trabalhistas e das condições de trabalho dos docentes nos últimos anos, perpassando pelo conceito e histórico de tal modelo econômico, bem como sua implantação no Brasil. A pesquisa possui caráter descritivo, abordagem quali-qualitativa e foi desenvolvida primordialmente por meio de estudo bibliográfico e análise de dados coletados por meio de questionários e entrevistas acerca das condições do trabalho e da saúde docente em diversas localidades do Brasil disponibilizados em diversas publicações científicas. Também foram utilizados dados do Instituto Brasileiro de Geografia e Estatística acerca da disparidade salarial entre homens e mulheres no Brasil em 2020.
\end{abstract}

*Corresponding author: Ana Carla Vaz Porto

Copyright $($ C 2021, Ana Carla Vaz Porto. This is an open access article distributed under the Creative Commons Attribution License, which permits unrestricted use, distribution, and reproduction in any medium, provided the original work is properly cited.

Citation: Ana Carla Vaz Porto, 2021. "Impactos do neoliberalismo e da reforma empresarial da educação sobre o trabalho docente", International Journal of Development Research, 11, (05), 46910-46915.

\section{INTRODUCTION}

Apesar do século XX ter sido marcado pela progressiva conquista e normatização de direitos trabalhistas ao redor do mundo, com a implantação do modelo econômico neoliberal passou-se a defender e implementar cada vez mais a "flexibilização" de tais direitos, o que na prática se traduz em verdadeira precarização das condições de labor. A deterioração das condições de trabalho também se faz sentir pelos docentes, já que a educação, mesmo a ministrada por instituições públicas, tem sido progressivamente inserida na lógica neoliberal. O presente artigo tem por objetivo demonstrar como o neoliberalismo e a reforma empresarial da educação no Brasil têm protagonizado a precarização dos direitos trabalhistas e das condições de trabalho dos docentes nos últimos anos, perpassando pelo conceito e histórico de tal modelo econômico, bem como sua implantação no Brasil.

\section{MATERIAIS E MÉTODOS}

A pesquisa possui caráter descritivo, abordagem quali-quantitativa e foi desenvolvida primordialmente por meio de estudo bibliográfico acerca do conceito e histórico do neoliberalismo, sua implantação no Brasil, interlocução de tal modelo econômico com o campo educacional e trabalhista e seus impactos sobre o trabalho docente. Também foram analisados dados coletados por meio de questionários e entrevistas acerca das condições do trabalho e da saúde docente em diversas localidades do Brasil disponibilizados em diversas publicações científicas. Finalmente, foram utilizados dados do Instituto Brasileiro de Geografia e Estatística acerca da disparidade salarial entre homens e mulheres no Brasil em 2020.

\section{DISCUSSÃO}

O neoliberalismo emerge da desordem do capitalismo após a segunda guerra mundial (HARVEY, 2011) sob a liderança de Friedrich von Hayek e da Mont Pelerin Society. Esse modelo econômico foi inserido na agenda dos países capitalistas em meados dos anos 1970 como resposta aos problemas estruturais do capitalismo emergentes naquele período. (COSTA et al, 2019) Tal momento histórico foi acompanhado pela elevação dos preços do petróleo e pela quebra financeira do mercado imobiliário global, que arrasou vários bancos e afetou as finanças dos Estados de forma drástica. Segundo os neoliberais, a crise seria solucionada se o Estado deixasse de atuar como agente econômico e se limitasse a construir um arcabouço institucional para garantir as liberdades individuais, utilizando-se do monopólio da violência para preservá-las. (COSTA et al, 2019). A privatização de ativos é uma das bandeiras neoliberais, pois seria uma das melhores maneiras de proteger as pessoas da "tragédia do bem comum" e alavancar o desenvolvimento econômico e social. (HARVEY, 2014). A competição também é um dos pilares do neoliberalismo e asseguraria a constante inovação de produtos, métodos e formas organizacionais, o que garantiria o movimento constante da máquina produtiva e impediria crises oriundas da saturação do mercado. Em função da crise estrutural do capitalismo na década de 1970, a economia norte-americana entrou em recessão e 
uma das consequências foi o endividamento das famílias, que comprometeram grande parte de sua renda com hipotecas. Os bancos do país estavam ávidos por novas oportunidades de investimentos, mas sua rentabilidade em território nacional estava estagnada devido a tal cenário. Assim, passaram a exportar capital e a cultivar novos mercados ao redor do mundo, realizando empréstimos maciços para países em desenvolvimento. (COSTA et al, 2019)

Nas décadas de 1970 e 1980, tais países entraram em crise devido às dificuldades para pagar seus empréstimos ante o aumento da taxa de juros (HARVEY, 2011). Tiveram, então, que recorrer ao Fundo Monetário Internacional que, por sua vez, condicionou a concessão de divisas à implementação de uma série de programas de ajuste estrutural alinhados ao neoliberalismo. (COSTA et al, 2019). O primeiro país a implementar tais programas foi o Chile em 1973, quando era governado pelo ditador Augusto Pinochet. Mais tarde, em 1989, o Consenso de Washington constituiu o marco para a implementação de políticas neoliberais em toda a América Latina. (COSTA et al, 2019). A partir de 1980, a onda neoliberal de privatizações varreu o mundo sob o escopo de que empresas estatais são ineficientes e desengajadas por definição, sendo que a única maneira de melhorar seu desempenho é transferi-las ao setor privado (HARVEY, 2011). Com isso, serviços de utilidade pública como fornecimento de água, eletricidade, telecomunicações e transporte foram inseridos na lógica de mercado e passaram a ser prestados por empresas privadas em diversos países. (COSTA et al, 2019). Na obra "O neoliberalismo - história e implicações", Harvey (2014) sintetiza tal modelo econômico nos seguintes termos:

O neoliberalismo é em primeiro lugar uma teoria das práticas político-econômicas que propõe que o bem-estar humano pode ser melhor promovido liberando-se as liberdades e capacidades empreendedoras individuais no âmbito de uma estrutura institucional caracterizada por sólidos direitos a propriedade privada, livres mercados e livre comércio. O papel do Estado é criar e preservar uma estrutura institucional apropriada a essas práticas; o Estado tem de garantir, por exemplo, a qualidade e a integridade do dinheiro. Deve também estabelecer as estruturas e funções militares, de defesa, da polícia e legais requeridas para garantir direitos de propriedade individuais e para assegurar, se necessário pela força, o funcionamento apropriado dos mercados. Além disso, se não existirem mercados (em áreas como a terra, a água, a instrução, o cuidado de saúde, a segurança social ou a poluição ambiental), estes devem ser criados, se necessário pela ação do Estado. Mas o Estado não deve aventurar-se para além dessas tarefas. (HARVEY, 2014, p. 12)

O Brasil foi o último país da América Latina a implementar o projeto neoliberal, o que se justifica pela dificuldade de unificação dos distintos interesses das diversas frações do capital presentes no país e também pela intensa atividade política desenvolvida pelas classes trabalhadoras na década de 1980 (constituição do Movimento dos Trabalhadores Sem Terra (MST), criação da Central Única dos Trabalhadores (CUT) e do Partido dos Trabalhadores (PT) e realização de cinco greves gerais entre 1983 e 1989). (FILGUEIRAS, 2006). No entanto, a mobilização política dos trabalhadores não conseguiu tornar hegemônico seu projeto nacional, democrático e popular, o que acabou possibilitando, a partir da eleição de Fernando Collor em 1989, a unificação das diversas frações do capital em torno do projeto neoliberal, mesmo com idas e vindas, contradições e disputas internas, em virtude do temor das classes dominantes de perderem o controle político da sociedade. (FILGUEIRAS, 2006)

Com o fracasso do Plano Cruzado e dos demais planos econômicos implementados no país na segunda metade da década de 1980, o projeto neoliberal foi se desenhando e fortalecendo, tornando-se progressivamente um programa político (FILGUEIRAS, 2006). Nos anos 1990, o neoliberalismo

que já havia adentrado na maior parte da América Latina, implanta-se no Brasil, com toda força, a partir do Governo
Collor. O discurso liberal radical, combinado com a abertura da economia e o processo de privatizações inaugura o que poderíamos chamar da "Era Liberal" no Brasil. Até então, apesar da existência de algumas iniciativas nesse sentido, durante o Governo Sarney, e de uma já forte massificação e propaganda dessa doutrina nos meios de comunicação de massa, havia uma forte resistência à mesma, calcada principalmente, na ascensão política, durante toda a década de 1980, dos movimentos sociais e do movimento sindical. (FILGUEIRAS, 2000, p. 83-84).

Bresser-Pereira (2017) defende que o neoliberalismo teria entrado em colapso com a crise financeira de 2008 , reiterada pela crise política do Brexit em 2016 na Inglaterra. No entanto, seria mais correto interpretar que, no melhor dos casos, tais eventos marcam o final da atual fase do neoliberalismo, a qual certamente será sucedida por outras. (FREITAS, 2018)

Apesar de, numa primeira leitura, ser possível se pensar o neoliberalismo como estratégia exclusivamente econômica, trata-se, como salientado por Pablo Gentili (1996) de um processo de construção hegemônica, um

projeto de reforma ideológica de nossas sociedades, a construção e a difusão de um novo senso comum que fornece coerência, sentido e uma pretensa legitimidade às propostas de reforma impulsionadas pelo bloco dominante. (GENTILI, 1996)

Segundo o autor, se o modelo neoliberal se transformou num verdadeiro projeto hegemônico, isto se deve ao fato de ter conseguido impor uma intensa dinâmica de mudança material e de reconstrução discursivo-ideológica da sociedade. (GENTILI, 1996). Tratando-se o neoliberalismo de um projeto ideológico hegemônico, não se descurou da educação, que tem sido amplamente transformada por meio da chamada reforma neoliberal ou empresarial. $\mathrm{O}$ neoliberalismo enxerga o campo educacional a partir de sua concepção de sociedade baseada em um livre mercado cuja própria lógica produz o avanço social com qualidade, depurando a ineficiência através da concorrência. Segundo essa visão, a generalização desta concepção para todas as atividades do Estado produzirá uma sociedade melhor e mais desenvolvida. (FREITAS, 2018). No Brasil, a principal meta da reforma neoliberal da educação é tirar as escolas de uma suposta crise de eficiência, eficácia e produtividade causada pelo processo de expansão ocorrido na segunda metade do século XX. (GENTILI, 1996)

Para os adeptos de tal corrente, as mudanças necessárias na educação brasileira são de ordem gerencial: é preciso tornar as práticas pedagógicas mais eficientes, flexibilizar a oferta educacional, modificar as estratégias de gestão para que se adequem ao conceito de qualidade total e reformular o perfil dos professores e dos currículos. (GENTILI, 1996). Tais mudanças, segundo os neoliberais, são atingidas por meio da desestatização das escolas e a consequente criação de um mercado educacional que fomente a competição de alunos e professores. Trata-se da replicação do perverso discurso da meritocracia segundo o qual têm sucesso os que mais se esforçam individualmente. Como sintetizado por Pablo Gentili (1996) "o neoliberalismo privatiza tudo, inclusive também o êxito e o fracasso social". Nesse contexto, as escolas e, consequentemente, os professores, são avaliados segundo os conceitos de qualidade total e produtividade, sendo instituído um sistema de recompensas (tanto simbólicas quanto materiais) aos que atingem as metas estipuladas. Para tanto, flexibilizam-se as formas de contratação e retribuições salariais dos docentes e se retira a autonomia pedagógica das instituições e atores coletivos da escola. (GENTILI, 1996)

Segundo os neoliberais, é preciso motivar as pessoas a trabalhar mais e aumentos salariais iguais para todos não seriam estimulantes, ao contrário de gratificações vinculadas a resultados. Com a instituição de tal sistema de metas, o trabalhador é avaliado apenas pelo produto final que produziu no prazo concedido, sendo irrelevante o fato de ter se empenhado mais que seu colega em determinada etapa, de ter tido que se ausentar do labor devido a alguma doença na constância do 
prazo, por exemplo, ou de não ter gerenciado o tempo de que dispunha de forma satisfatória. A despeito de qualquer imprevisto ou variante que tenha ocorrido, o trabalhador será mensurado pelo atingimento ou não da meta prevista, sendo que esta é quase sempre estipulada acima da média para "estimular o empenho dos funcionários". Na educação, tal sistema de metas é atrelado, por exemplo, ao desempenho dos estudantes em testes: o resultado atingido pelos alunos passa a ser um dos parâmetros utilizados para dimensionar complementações salariais variáveis e personalizadas para os professores. Segundo tal visão, o docente trabalhará mais se estiver com sua cabeça a prêmio todo dia. (FREITAS, 2018) No Brasil, o estado de São Paulo é o que mais exaustiva e persistentemente utilizou tal política de bônus por mérito. Recentemente, veio à tona que os bônus foram mantidos, apesar de sua ineficácia, por uma decisão política. (FREITAS, 2018)

Sob a ótica neoliberal, também é desejável que o professor se identifique totalmente com a missão da escola na qual trabalha, assumindo como seus os interesses de seu empregador, em detrimento de seus interesses particulares. Em outras palavras, ocorre uma refeudalização das relações sociais de produção, sendo o trabalhador transformado no orgulhoso vassalo de uma firma. Para tanto, priorizase contratação de professores jovens, pois, em sua maioria, nunca se filiaram a qualquer sindicato e não possuem identidade de classe, não tendo ainda exata consciência de seu lugar na sociedade. A estes jovens se oferece não apenas um emprego, mas uma "identidade", com comportamento, modo de vestir e vocabulário próprios da "casa". Em outras palavras, o professor, além de passar a ter um trabalho do qual possa se orgulhar, passa a pertencer a uma "grande família".

André Gorz (2004), em passagem do livro "Misérias do presente, riqueza do possível", analisa esta prática de forma muito crítica e pertinente, conforme segue:

Em uma sociedade em vias de decomposição, na qual a busca de identidade e interação social é constantemente frustrada, o jovem encontra na cultura e patriotismo da empresa um refúgio contra o sentimento de insegurança. A firma o conforta, substitui a sociedade global. (GORZ, 2004)

Em retribuição a este acolhimento do professor pela escola, exige-se que ele renuncie a qualquer outra forma de pertencimento, a seus interesses anteriores, à sua vida pessoal e à sua própria personalidade para se entregar "de corpo e alma" à instituição. Na maioria das vezes, essa exigência não é verbalizada, mas fica muito clara logo nos primeiros meses de labor, pois a carga de trabalho é tamanha que exige dedicação praticamente integral ao emprego e o abandono de toda e qualquer atividade que se exercia anteriormente. No modelo neoliberal, o laço que une o docente à escola passa a ser o único ou o principal elo social de que este sujeito dispõe, pois absorve toda a sua energia e o mobiliza como um todo, tendo em vista que tem que se desdobrar para atingir as inalcançáveis metas que lhe são impostas, pois, caso não as atinja, muito provavelmente será substituído por alguém mais competente. Além do temor de ser dispensado, o professor inserido em tal modelo educacional também atribui a si a obrigação moral de atender plenamente aos interesses da escola e atingir suas metas, pois, por imposição da sociedade em decomposição mencionada por Gorz (2004), este passa a ser o grande sentido de sua vida, sendo que a perda do emprego equivaleria à perda de si mesmo.

$\mathrm{O}$ fato de o neoliberalismo ter se disseminado vários anos após o auge das lutas sindicais e proletárias fez com que o cenário encontrado fosse bem distinto do verificado nos tempos do fordismo e do taylorismo. Não mais havia o sentimento de que os trabalhadores deveriam estar em constante luta contra seus empregadores, pois várias de suas reivindicações já haviam sido atendidas e normatizadas. Isto, somado às diversas publicidades que objetivam incutir nas pessoas a ideia de que o trabalho torna todos mais felizes, realizados e prestigiados, tem possibilitado uma mudança significativa na forma como a sociedade entende o labor. Se até o início do século XX ainda era presente a ideia de que o trabalho traduzia a exploração dos empregados pelos empregadores, na era neoliberal ele é encarado de forma extremamente positiva e como motivo de orgulho. Esta mudança de parâmetros tem sido reforçada pela consolidação da sociedade de consumo. Como uma das estratégias do neoliberalismo é criar nas pessoas, por meio da publicidade, o desejo de adquirir novos bens sob o escopo de que os seus já se tornaram obsoletos, o consumismo tem se solidificado progressivamente e, com ele, a necessidade de que se obtenha cada vez mais renda para que sejam supridos os desejos por mercadorias. Neste contexto, o trabalho passou a ser visto como algo a ser buscado a qualquer custo, pois um sujeito sem dinheiro e, portanto, que não tem condições de adquirir os bens desejados por todos, é desprezado socialmente. Outro fator que contribuiu para a supervalorização do trabalho foi o aumento do desemprego à época da implantação do neoliberalismo. Neste cenário, o trabalho é encarado como um bem extremamente valioso e desejado, porém escasso, o que configura terreno fértil para o desrespeito aos direitos trabalhistas e para a precarização das condições de labor.

Como o professor inserido no modelo neoliberal está constantemente sujeito ao imperativo da competitividade, teme a todo momento o desemprego e se vê na constante necessidade de auferir mais renda para satisfazer seus desejos de consumo e obter prestígio social. A consequência inarredável é que, para isso, se submete a quaisquer condições impostas por seu empregador, por mais precárias que sejam. Se anteriormente os motins e paralizações de professores eram bastante temidos, no neoliberalismo os docentes são constantemente assaltados pelo temor do desemprego, de forma que se empenham ao máximo para atender aos interesses da escola onde trabalham, ainda que para isso tenham que extrapolar sua jornada diária, suprimir seu descanso semanal e seus intervalos para descanso e refeição. Além da nova ideologia que favorece o desrespeito aos direitos trabalhistas dos docentes, a implantação do neoliberalismo é acompanhada pela criação de instrumentos jurídicos que possibilitam a precarização de tais direitos, como a terceirização de serviços, a possibilidade de redução salarial por meio de normas coletivas, a extensão das jornadas por meio do banco de horas e a pejotização ${ }^{1}$. Outra ideia difundida pelo neoliberalismo é que os sindicatos são responsáveis diretos pela "crise gerencial" da educação, pois constituem empecilhos para o desenvolvimento dos mecanismos de competição individual dos docentes que supostamente garantem o progresso social (GENTILI, 1996). Nesse contexto, a sindicalização dos professores é malvista e desestimulada pelos empregadores e até mesmo pelo Estado, ainda que de forma velada.

Como sintetizado por Buchanan, um dos expoentes do neoliberalismo, todo o mal começa quando os indivíduos, que isoladamente não têm poder, se juntam e formam movimentos para se fortalecer numericamente e influenciar o governo, fazendo com que este ouça seus desejos e atue por eles. (FREITAS, 2018). No Brasil, o projeto neoliberal de desmonte dos sindicatos tem sido claramente implementado. Basta considerar, por exemplo, que a reforma trabalhista aprovada em 2017 (Lei $\mathrm{n}^{\circ}$ 13.467/17) selou o enfraquecimento dos entes sindicais (e até mesmo a extinção de alguns) ao suprimir o que até então era sua maior fonte de renda, a contribuição sindical que antes era obrigatoriamente paga por todos os integrantes da categoria, sindicalizados ou não.

Com o sindicato enfraquecido, o professor está muito mais vulnerável aos desmandos de seu empregador e à degradação de suas condições de trabalho. Além disso, por receio de serem malvistos pelo empregador ou por julgarem desimportante o trabalho do sindicato, muitos docentes não se sindicalizam e com isso se perde gradativamente o sentimento de classe, de que se pertence a uma entidade maior e mais forte capaz de resistir às imposições patronais. Dessa forma, o professor fica muito mais propenso a aceitar

\footnotetext{
${ }^{1}$ Contratação de serviços exercidos por pessoas físicas de modo pessoal, subordinado, não eventual e oneroso, por meio de pessoa jurídica constituída especialmente para esse fim, na tentativa de desconfigurar a relação de emprego e burlar direitos trabalhistas.
} 
condições a princípio inaceitáveis por não vislumbrar meios de, individualmente, se opor a elas.

\section{Como aponta Giroux (2017):}

A antiga linguagem dos direitos coletivos deu lugar ao discurso dos direitos individuais, e o vocabulário da colaboração e solidariedade foi deslocado pelo discurso do individualismo radical e o ethos áspero da sobrevivência do mais forte. A "liberdade" se transformou em sinônimo de interesse próprio desenfreado e em uma razão para abdicar de qualquer senso de responsabilidade moral e política. (tradução livre) (GIROUX, 2017)

Outro ponto bastante relevante na reforma neoliberal da educação é a diminuição da autonomia pedagógica docente por meio do estabelecimento de uma base nacional comum curricular e da imposição de que os professores utilizem materiais didáticos préestabelecidos e padronizados. (FREITAS, 2018). Trata-se de terreno fértil para que ganhem fôlego outros movimentos destinados a cercear a liberdade docente como o "escola sem partido", que assim como o neoliberalismo enxerga esquerdismo e comunismo em tudo que se relaciona à defesa dos interesses populares pelo Estado. (FREITAS, 2018)

Para os neoliberais, no cenário mais desenvolvido, não há necessidade de que o Estado se preocupe com a qualificação de professores, organização das escolas e suas condições de funcionamento. $\mathrm{O}$ mercado, através da concorrência, vai moldando (e precificando) as propostas feitas pelas escolas e cuida das condições de qualificação e oferta. Nesse caso, as provedoras de educação privada são empresas operando com os procedimentos típicos da organização empresarial. Quem não segue tal cartilha vai à falência e é eliminado do mercado. Assim, é o mercado que faz a depuração da qualidade, pois escolas de pouca qualidade não serão escolhidas pelos pais e irão à falência como qualquer empresa. (FREITAS, 2018). Nessa lógica, as escolas de menor qualidade devem sucumbir às de maior qualidade, sendo fechadas; os estudantes de menor desempenho devem sucumbir aos que têm melhor performance, sendo barrados em sucessivos testes; os professores de menor qualidade devem ser substituídos pelos mais bem preparados, sendo demitidos. (FREITAS, 2018). Trata-se do que Gentili (1996) satiricamente denomina de "mcdonaldização da escola": a transferência dos princípios que regulam a lógica de funcionamento dos fast foods a espaços institucionais, passando as escolas a serem pensadas e reestruturadas sob os padrões produtivistas e empresariais.

Nesse cenário, segundo os neoliberais, o magistério deve ser inserido em um livre mercado competitivo em que os salários são tornados dependentes dos resultados esperados, sem direito à estabilidade no emprego e tanto quanto possível sem sindicalização. Estabilidade, salários equânimes, previdência e sindicalização são condições altamente indesejáveis por supostamente impedirem o mercado de produzir qualidade na escola. (FREITAS, 2018). Como consequência, os docentes têm sido gradativamente atingidos pelo mesmo processo de precarização que tem degradado as condições de trabalho de diversos outros nichos profissionais. Souza et al. (2003) corroboram tal posição pontuando que, até os anos 1960, a maior parte dos trabalhadores do ensino brasileiro gozavam de relativa segurança material, emprego estável e de certo prestígio social, o que mudou a partir dos anos 1970, quando o papel do professor extrapolou a mediação do processo de conhecimento do aluno. Ampliou-se a missão do docente para além da sala de aula e exigiu-se dele dedicação mais ampla aos objetivos da escola, o que se traduziu em aumento da carga de trabalho e deterioração das condições de labor.

José Contreras (2002) faz coro à precarização do trabalho docente afirmando que ele sofreu e vem sofrendo uma progressiva subtração de qualidades que tem conduzido os professores à perda de controle, autonomia e sentido sobre o próprio trabalho, o que o autor sintetiza com o termo proletarização.
Dados coletados em diversas localidades do país comprovam tal proletarização e seus efeitos nocivos sobre a saúde dos docentes. Assunção, Barreto e Gasparini (2005) analisaram relatório emitido pela Gerência de Saúde do Servidor e Perícia Médica da Prefeitura Municipal de Belo Horizonte, Minas Gerais, e constataram que, entre abril de 2001 e maio de 2003, os transtornos psíquicos ficaram em primeiro lugar entre os diagnósticos que provocaram afastamentos dos funcionários da Secretaria Municipal de Educação (em sua maioria professores). $\mathrm{Na}$ sequência, estão os diagnósticos relacionados a doenças do aparelho respiratório e doenças do sistema osteomuscular e do tecido conjuntivo.

A investigação das condições de saúde e trabalho de professores da rede particular de ensino do estado da Bahia destaca uma grande proporção de adoecimento numa população relativamente jovem, com queixas importantes relacionadas ao funcionamento psíquico, como cansaço mental e nervosismo. Em tal estudo, os professores citaram as seguintes queixas de saúde: dor na garganta, dor nas pernas e costas, rouquidão e cansaço mental. As características do trabalho associadas às queixas foram: salas inadequadas, trabalho repetitivo, exposição ao pó de giz, ambiente de trabalho estressante, ritmo acelerado de trabalho, desempenho das atividades sem materiais e equipamentos adequados e posição de trabalho incômoda. (ARAÚJO et al, 1998). Também foi realizado estudo na rede particular de ensino da cidade de Vitória da Conquista (Bahia) com grupo de professores que atuam da pré-escola ao ensino médio. Os resultados apontam uma população jovem (idade média de 34,5 anos), composta principalmente por mulheres $(83 \%)$, em sua maioria casadas $(65 \%)$ e com nível de escolaridade superior $(72 \%)$, sendo que mais da metade $(52 \%)$ trabalhava em outra escola. Entre as queixas de saúde apresentadas destacaram-se: cansaço mental $(60 \%)$, dor nos braços e ombros $(52 \%)$, dor nas costas $(51 \%)$, formigamento nas pernas (47\%), dor na garganta (46\%) e rouquidão $(60 \%)$. (DELCOR et al, 2004). Codo (1999) estudou uma amostra de quase trinta e nove mil trabalhadores da educação em todo o Brasil e identificou que $32 \%$ dos indivíduos apresentavam baixo envolvimento emocional com a tarefa e $25 \%$ se encontravam com exaustão emocional. Ao tratar dos elementos que poderiam estar associados a tais queixas, o autor pontuou que o trabalho do professor não se restringe ao exercício de sua função na sala de aula, exige atualização e preparação constantes e muitas tarefas são realizadas sem a presença dos alunos, fora da sala de aula e, frequentemente, fora da escola. Quando o professor ministra aulas em várias turmas para alunos em níveis de ensino, escolas e turnos diferentes, a preparação das aulas requer avaliações múltiplas e esquemas variados, sendo necessário maior investimento de tempo na execução de um volume maior de trabalho, mais dedicação e grande esforço intelectual. $\mathrm{O}$ autor enfatiza também o investimento emocional dos professores, na medida em que diariamente estabelecem vínculos que extrapolam o âmbito profissional com os alunos, outros professores e funcionários da escola.

A Organização Internacional do Trabalho (OIT) aponta que, desde 1983, a classe docente é a segunda categoria profissional, em nível mundial, a portar doenças de caráter ocupacional, que vão desde reações alérgicas a giz, distúrbios vocais, gastrite e até mesmo esquizofrenia. O estresse que acomete os professores não é considerado pela OIT como um fenômeno isolado, mas como um risco ocupacional significativo da profissão. (TOSTES et al, 2018)

\section{Como sintetizado por Assunção, Barreto e Gasparini (2005):}

Os dados e as conclusões dos estudos interessados em descrever o perfil de adoecimento dos professores são convergentes, independentemente da população e da região estudada. Observou-se que os professores têm mais risco de sofrimento psíquico de diferenciados matizes e a prevalência de transtornos psíquicos menores é maior entre eles, quando comparados a outros grupos. (ASSUNÇÃO et al, 2005)

É inegável, portanto, os efeitos nocivos do neoliberalismo e da reforma empresarial da educação sobre as condições de trabalho dos 
docentes, o que tem se refletido de forma bastante negativa na saúde física e psíquica dos integrantes de tal nicho profissional.

Não se pode perder de vista a estreita relação entre a precarização do trabalho docente no Brasil e o fato de que a maioria de tais profissionais são mulheres. Como ocorre em outras profissões, a presença massiva do sexo feminino no magistério aliada ao machismo estrutural de nossa sociedade provoca a desvalorização da categoria. Araújo e Durães (2010) sintetizam tal cenário alegando que "as formas de ocupação nas quais as mulheres estão inseridas representam, em sua maioria, relações de trabalho que levam inevitavelmente, à desproteção social, ainda que sob uma aparente inclusão laboral formal”.

\section{Carranza (2016) corrobora tal posição alegando que}

A profissão no magistério passou a ser cada vez mais dominada pelas mulheres devido à insatisfação dos homens pela baixa remuneração salarial. Para que pudessem sustentar a sua família, cabia-lhes procurar profissões mais rentáveis. No mesmo sentido, Apple (1988), já havia percebido em suas pesquisas que a feminização no magistério se deve em grande parte do fato que os homens desprezaram essa profissão. (CARRANZA, 2016)

A visão de que a docência, sobretudo a direcionada a crianças, e as demais profissões majoritariamente exercidas por mulheres, constituem extensão das atividades domésticas historicamente atribuídas ao gênero feminino, contribui para a desvalorização social e econômica de tais atividades e isso se reflete nos salários pagos a tais trabalhadoras: em 2020, o salário médio das trabalhadoras brasileiras foi no valor de R $\$ 2.191,00$, enquanto o dos pertencentes ao sexo masculino foi no importe de $\mathrm{R} \$ 2.694,00$ (IBGE, 2021). A diferença de valores aumenta ainda mais quando se consideram as ocupações que exigem nível superior: em 2020, elas receberam em média R\$ 4.913,00 ocupando tais postos, enquanto o valor médio pago a eles foi de R $\$ 8.136,00$. (IBGE, 2021). Também não se pode deixar de salientar que a pandemia da COVID-19 agravou substancialmente as condições nocivas do trabalho docente em 2020 e 2021, já que a maioria dos professores passou a ter que dar aulas de suas casas sem o menor preparo para tanto.

Muitos não tinham e não têm local próprio para fazê-lo, internet adequada para tanto e tampouco conhecimento suficiente para lidar com as novas plataformas de ensino. Ainda assim, muitas vezes sem o apoio da escola, tiveram que readequar todo o processo de ensino para que as atividades letivas prosseguissem.

Segundo Zaidan e Galvão (2020):

Professoras e professores experimentaram uma mudança brusca em suas rotinas, que se caracteriza pela penetração insidiosa do trabalho em todos os espaços e momentos de seu cotidiano, não importando que seus empregadores (o governo ou os donos de escola) não lhes tenham garantido estrutura para o teletrabalho (ZAIDAN et al, 2020, p. 264).

Inegavelmente, a transformação súbita do trabalho, a ausência de fronteiras entre o âmbito profissional e o pessoal e o medo generalizado em decorrência da crise sanitária enfrentada em todo o mundo degradam ainda mais as condições do trabalho docente já precarizadas pelo neoliberalismo e pela reforma empresarial da educação.

\section{RESULTADOS}

Tratando-se o neoliberalismo de um processo de construção hegemônica, alterou não apenas a economia brasileira, mas nossa sociedade como um todo e a ideologia que a domina. A concepção de livre mercado e de avanço social por meio da concorrência e da superação da ineficiência passou a ser aplicada a todos os campos, inclusive o educacional, que tem sido amplamente transformado por meio da chamada reforma neoliberal ou empresarial da educação. Tal reforma visa tirar as escolas de uma suposta crise de eficiência, eficácia e produtividade por meio da criação de um mercado educacional que fomente a competição de alunos e professores. Segundo os neoliberais, o magistério deve ser inserido em um livre mercado competitivo em que os salários são tornados dependentes dos resultados esperados, sem direito à estabilidade no emprego e tanto quanto possível sem sindicalização. Estabilidade, salários equânimes, previdência e sindicalização são condições altamente indesejáveis por supostamente impedirem o mercado de produzir qualidade na escola. Como consequência, os docentes têm sido gradativamente atingidos por um processo de precarização de suas condições de trabalho que têm afetado sua saúde física e mental. Apesar de não se vislumbrar, no médio prazo, um cenário no qual a educação e o trabalho docente deixem de estar submetidos aos ditames do neoliberalismo, entender como tal modelo opera e seus impactos negativos é fundamental para que se possa organizar a resistência.

\section{REFERENCIAS}

ALVES, Giovanni. O novo e precário mundo do trabalho Reestruturação produtiva e sindicalismo no Brasil. São Paulo: Boitempo, 2000.

ARAÚJO, Ângela Maria Carneiro; DURÃES, Bruno José Rodrigues. Informalidade e desproteção social: uma realidade para a maioria das mulheres trabalhadoras. In: COSTA, Albertina (Org). Divisão Sexual do Trabalho, Estado e Crise do Capitalismo. Recife: SOS CORPO, 2010. P. 83-114.

ARAÚJO, T. M.; SILVANY-NETO, A. M. (organizadores). Condições de trabalho e saúde dos professores da rede particular de ensino. Sindicato dos Professores no Estado da Bahia/ Universidade Federal da Bahia/ Confederação Nacional dos Trabalhadores em Estabelecimentos de Ensino. Salvador, set. 1998 , p. 5-42.

ASSUNÇÃO, Ada Ávila; BARRETO, Sandhi Maria; GASPARINI, Sandra Maria. O professor, as condições de trabalho e os efeitos sobre sua saúde. In: Educação e Pesquisa. São Paulo, v. 31, n. 2, p. 189-199, maio/ago. 2005.

BRESSER-PEREIRA, Luiz Carlos. The two forms of capitalism: developmentalism and economic liberalism. In: Brazilian Journal of Political Economy, v. 37, n. 4 (149), p. 680-703, 2017. Disponível em $<\mathrm{http} / /$ www.bresserpereira.org.br/ papers/2017/347-Two-Forms-Capitalism.pdf $>$. Acesso em 21 abr. 2021.

CARRANZA, Kátia Augusta Coutinho. Educação da mulher no Brasil e magistério. 2016. Disponível em < https://portal.fslf.edu.br/wpcontent/uploads/2016/12/TCC_Katia.pdf $>$. Acesso em 22 dez. 2020.

CODO, W. (organizador). Educação: carinho e trabalho. Petrópolis: Vozes, 1999.

CONTRERAS, José. A autonomia de professores. São Paulo: Cortez, 2002.

CORIAT, Benjamin. Pensar pelo avesso - o modelo japonês de trabalho e organização. Traduzido por Emerson S. da Silva. Rio de Janeiro: Revan: UFRJ, 1994.

COSTA, Camila Furlan da; SILVA, Sueli Maria Goulart. Novo neoliberalismo acadêmico e o ensino superior no Brasil. In: Revista eletrônica de administração (Porto Alegre), v. 25, n. 3, 2019. Disponível em <https://www.scielo.br/scielo.php? script $=$ sci_arttext\&pid $=$ S1413-23112019000300006>. Acesso em 21 abr. 2021.

DELCOR, N., S. et al. Condições de trabalho e saúde dos professores da rede particular de ensino de Vitória da conquista, Bahia, Brasil. In: Cadernos de Saúde Pública, Rio de Janeiro, v.20, n.1, p. 187-196, jan.-fev. 2004.

FILGUEIRAS, Luiz. A história do Plano Real: fundamentos, impactos e contradições. São Paulo: Boitempo, 2000.

FILGUEIRAS, Luiz. O neoliberalismo no Brasil: estrutura, dinâmica e ajuste do modelo econômico. In: Neoliberalismo y sectores 
dominantes. Tendencias globales y experiencias nacionales. BASUALDO, Eduardo M.; ARCEO, Enrique (organizadores). Consejo Latinoamericano de Ciencias Sociales: Buenos Aires, 2006. Disponível em $<$ http://biblioteca.clacso.edu.ar/ ar/libros/grupos/basua/C05Filgueiras.pdf $>$. Acesso em $21 \mathrm{abr}$. 2021.

FREITAS, Luiz Carlos de. A reforma empresarial da educação: nova direita, velhas ideias. São Paulo: Expressão Popular, 2018.

GENTILI, Pablo. Neoliberalismo e educação: manual do usuário. In: SILVA, Tomaz Tadeu da; GENTILI, Pablo (organizadores). Escola S. A.: quem ganha e quem perde no mercado educacional do neoliberalismo. Brasília: CNTE, 1996

GIROUX, H. A. Trump's neo-nazis and the rise of illiberal democracy, 2017. Disponível em <https://truthout.org/articles/ neo-nazis-in-charlottesville-and-the-rise-of-illiberaldemocracy>. Acesso em 8 abr. 2021.

GORZ, André. Misérias do presente, riqueza do possível. Traduzido por Ana Montoia. São Paulo: Annablume, 2004.

HARVEY, David. O enigma do capital: e as crises do capitalismo. São Paulo: Boitempo, 2011.

HARVEY, David. O neoliberalismo - história e implicações. São Paulo: Loyola, 2014.

IBGE. Pesquisa nacional por amostra de domicílios contínua. 2021. Disponível em: < https://www.dieese.org.br/outraspublicacoes/ 2021/graficosMulheresBrasilRegioes2021.pdf >. Acesso em 19 mar. 2021.
NORONHA, M. M. B. Condições do exercício profissional da professora e dos possíveis efeitos sobre sua saúde: estudo de casos das professoras do ensino fundamental em uma escola pública de Montes Claros, Minas Gerais. Dissertação (Mestrado) Faculdade de Medicina da UFMG. Belo Horizonte, 2001. 157 p.

SOUZA, Kátia Reis; SANTOS, Maria Blandina Marques dos; PINA, José Auguto; MARIA, Amabel Bianca Vial; CARMO, Maria Auxiliadora T.; JENSEN, Mirdney. Trajetória do Sindicato Estadual dos Profissionais da Educação do Rio de Janeiro (SEPE-RJ) na luta pela saúde no trabalho. In: Ciência e Saúde Coletiva, v. 8, n. 4, p. 1057-1068, 2003.

STANDING, Guy. O precariado: a nova classe perigosa. Traduzido por Cristina Antunes. São Paulo: Autêntica, 2013.

TOSTES, M. V. et al. Sofrimento mental de professores do ensino público. In: Saúde em Debate, vol. 42, n. 116, 2018.

WOOD, Stephen. $O$ modelo japonês em debate: pós fordismo ou japonização do fordismo. Traduzido por Vera Pereira. Disponível em <http:/www.anpocs.org.br/portal/publicacoes/ rbcs_00_17/rbcs17_03.htm>. Acesso em 07 abr. 2021.

ZAIDAN, J. M.; GALVÃO, A. C. COVID19 e os abutres do setor educacional: a superexploração da força de trabalho escancarada. In: AUGUSTO, C. B.; SANTOS, R. D. (organizadores). Pandemias e pandemônio no Brasil. São Paulo: Instituto Defesa da Classe Trabalhadora, 2020. 